\title{
Leading Strategy and Decision Making in Production Enterprises in Kosova
}

\author{
Muhamet HALILI ${ }^{\star}$, Betim SPAHIU ${ }^{\star \star}$, Kushtrim ZEBICA ${ }^{\star \star \star}$, Muhamet SPAHIU $^{\star \star \star \star}$
}

\begin{tabular}{l}
\hline \multicolumn{1}{c}{ A R T I C L E I N F O } \\
\hline Article history: \\
Accepted April 2021 \\
Available online May 2021 \\
\hline JEL Classification \\
E23, L23, M11, D24, D7 \\
Keywords: \\
Leadership, management, decision \\
making, strategy and styles
\end{tabular}

making, strategy and styles

\begin{abstract}
A B S T R A C T
This paper introduces how substantial decision-making and leadership styles relates with each other in production entreprises. One of the most important issues in the work and operation of each managerial structure is undoubtedly the decision making on all the issues that are the competence of managers of any level. Although within companies sometimes decisions are made by other enterprises, however the most important decisions are always the responsibility of the managers and management of enterprise. Management in general can be considered a process of working and relationships with others and with the help of others to achieve the goals of the company or enterprise, operating in an ever-changing environment and using effective limited resources. So, management fulfils the role precisely by the decisions made. A good manager should also be a good leader as well. In contemporary conditions in which manufacturing companies operate nowadays, there will not be any success if they do not have the right leader.
\end{abstract}

(c) 2021 EAI. All rights reserved.

\section{Introduction}

We can ascertain that there is no area of human activities where decisions are not made, so decision makers also have certain responsibilities over decisions. Thus, we can say that the higher level of decisionmaking is, the decision has a greater weight and power, because it "affects" the largest number of members of the enterprise, but at the same time, if the decision is wrong, there can be consequences for the whole company.

A large number of professional and scientific research from the field of management and decision making were attained in the second half of the last century. Many of these researches, firstly emphasized the role of the attributes the leader possessed, then emphasizing his behaviour and power, while at the end of the century it was emphasized the environment in which the leader acted. This approach influenced the creation of certain theories and empirical research according to which all leaders can be classified in the style of leadership, between autocrats and democrats, as two extreme decision-making styles. However, many styles of decision making depend on the characteristics of the decision maker, the characteristics of collaborators, and the specifics of the situation in which decision making takes place. From this, we can say that in the quality of the decision made by a manager, the main influence is on the skills and knowledge of the manager, the abilities of his partner, as well as the situation and circumstances at the moment of the decision. Depending of these three components, managers usually can apply different leading styles.

\section{Methodology}

Research methodologies applied in the framework of this research paper, include office research and field research, which means - a series of research conducted by visiting some of the Kosovo manufacturing companies in which the appropriate survey and interviews were conducted, in order to examine the hypotheses laid out in the theoretical review of the paper. For the realization of this scientific work we have used the methods of in-depth review of the available literature, in-depth internet research related to the achievements in the field that is the subject of the review in this paper. The method of induction as well as the method of deduction, the method of analysis, synthesis and finally - the method of description have been applied. With the full combination of research diversity, we have try to realize the main premise of scientific research, which is the description, or description of subjects and phenomena which are the subject of scientific review. 


\section{Basic principles of Leadership}

Leadership can be defined both as a process and performance. As a process, leadership is characterized by a continuous influence in shaping group or company goals, in motivating the behaviours and actions that help achieve goals, and in helping define and create an appropriate individual, group and organizational culture within a company. As a performance, leadership represents a group of specific individual traits possessed by those people who are accepted as leaders by a particular group of people.

\subsection{The definition of a Leader}

Leader is the person who influences other members of a group, the person who encourages people into so-called social situations, plans and organizes actions thereby encouraging others to engage and collaborate on the issue. A leader is at the top of a group, inspires others and helps members reach their goals by maximizing their individual abilities. One of the basic characteristics of a leader is the ability to shape the vision and push people towards its realization, focusing on the future. A leader, on the other hand is expected to have appropriate behaviours in relation to the "submissive," and this behaviour may be explicit or implicit and subjected to some general rules, so each leader is reminded for something particular in their actions or behaviours. In general, a leader must have certain special characteristics, which the following can be distinguished:

- Authorizing to delegate his competencies to his assistants, fully involving them in shaping goals and planning activities;

- Proper intuition in anticipating changes and in taking action to eliminate or minimize the impact of changes, using future changes to the benefit of the company while acknowledging the potential risks.

- Self-understanding, which enables the leader to perceive strengths and find opportunities to compensate weaknesses.

- Vision that includes the leader's ability to identify the best working environment, as well as finding opportunities for adequate communication with the surrounding environment, to secure them from potential impacts that would damage the company;

- Coordinate values that include leader's ability to identify the value of the company, as well as the value of individuals and their harmonization for mutual benefit.

In fulfilling a role, a leader applies a certain style, which means behaviours, actions and influence of the group members or company. This style is usually a combination of individual beliefs, values, and preferences, as well as the organizational culture and norms that impose to favour one style over another.

Classifying leaders based on the style they can apply, there are several approaches known today. Here we are separating the classification according to Goleman / Boyatzis / McKee [3]. They highlight 6 types of leadership that are characterized by different effects:

- Visionary type leader

- Instructional type leader;

- Affiliative type leader;

- Democratic type leader;

- Setting the tone type leader

- Commander type leader;

Yet despite these diametric differences, there are many actions within a leader's activities that are the same for each type of leader. With this issue, a large number of management experts and other scholars have already dealt, so here are just a few of the activities that apply all types of leaders (same actions, regardless of type):

- Coordination of group activities;

- Activation and intercession in intergroup conflicts;

- In-depth explanations of goals, expression of vision and group inspirations;

- Proper explanations and solutions;

- Initiating and accelerating activities;

- Representing the group or company in front of others from outside and within groups;

- Providing security and optimism in difficult situations;

- Primary division and remuneration division;

- Group integration

- Continuous refresh of groups and their development;

Here we come to a comparative conclusion: a good leader does not necessarily have managerial skills, but on the other hand a manager who claims to be successful must necessarily possess the skills of a leader, since with these qualities a manager must also be a leader, integrating various qualities that give the company the proper competitive edge. 


\subsection{Leadership and decision-making styles}

Decision-making styles are usually in close correlation with leadership styles. By analysing leadership styles, a leader must first be at the centre of interest, analysing and examining only behaviours, but not attributes or abilities. So, in this way and with this approach, we focus exclusively on what a leader does and works, that is, on understanding human behaviour and meeting workplace needs, always measuring these with organizational performance improvement.

Even in terms of examining leadership styles, a lot of scientific research has been done and here we will highlight the most dominant ones:

- Power-based leadership;

- Autocratic- Democratic leadership;

- Task-oriented or employee-led leadership;

- Leadership oriented towards full consideration of structures;

- Leadership according to the Likert system;

- Network of Leaders.

\subsection{The three classical styles of leadership}

Research shows that a considerable number of leadership styles have been developed (figure 1), which are situated between two extremes - on one hand they form autocratic styles, and on the other hand they contain the set of styles labelled with the French term "lasses-faire" (in English: "it's never late, "or" stay calm").

In any case, leaders make various efforts to motivate people behave and act in harmony and towards the achievement of organizational and other company goals. If their approach places emphasis on rewards (pay rise or similar to this), it can be said that such a leader is using a positive style. On the other hand, if a leader threatens and punishes, we can say that he is applying negative leadership. Satisfactory educational level and proper professional training of workers, requirements and efforts of the company to enjoy greater independence and other factors, can create a feeling of satisfaction among employees, so in this case, they are practically made dependent and closely related to positive type leadership. On the other hand, in most cases, negative leadership has bad impact on people. In such cases, a leader in order to force employees to perform their duties, puts pressure on them by threatening and often punishing them with dismissal, reprimanding them in the presence of others and sometimes suspending them. So, a leader of this kind uses the position, holding on to the illusion that the measures taken will "frighten" employees, which would result in productivity and other good results.

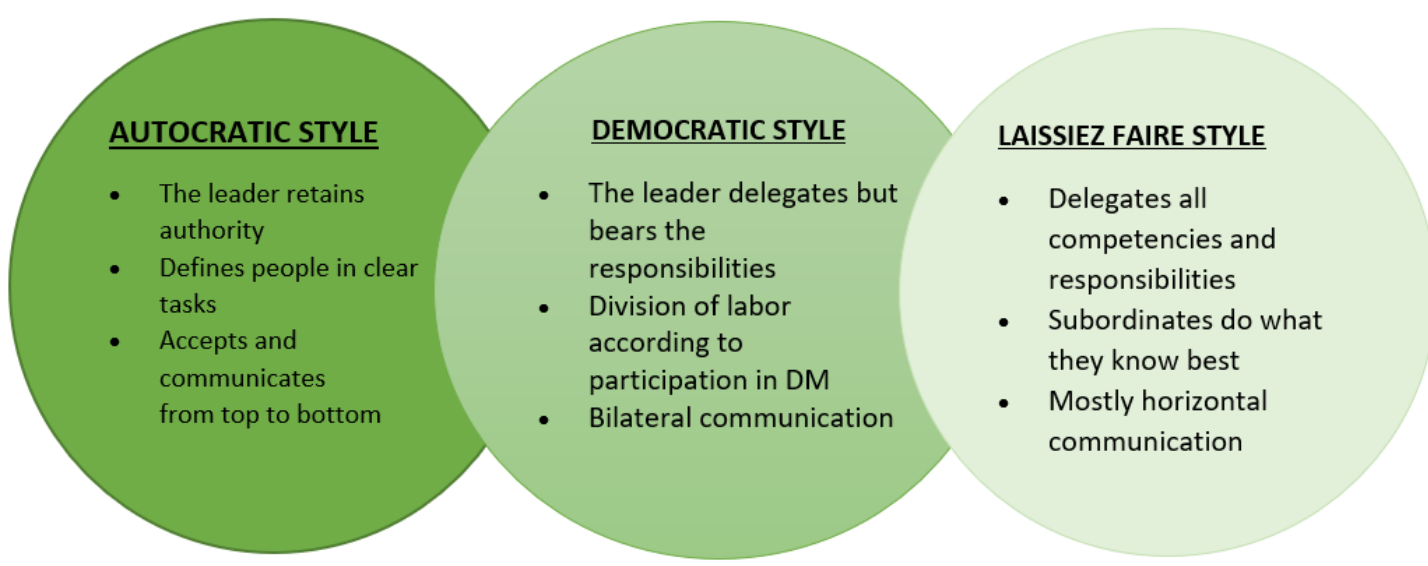

Figure 1. The three classical styles of leadership

Source: Lewin, K.; Lippitt, R.; White, R.K. (1939). Patterns of aggressive behaviour in experimentally created social climates. Journal of Social Psychology 10: 271-301

The authoritative style leader gives oneself all the power and "right" to authoritative and unquestionable decision making and expects from employees carrying out the orders only, takes full responsibility for all decisions, but also plays the role of overall control over the fulfilment of individual obligations. Authoritarian leadership is based on intimidation, threats and condemnation. The advantage of this leadership style lies in the fact that it always results in a visible satisfaction of the leader, enables quick decision-making and enables complete control of those who have to make decisions. However, most employees do not enjoy this style, especially when this style generates fear and frustration. Therefore, this style is not preferred in large companies, since in this case the top-level manager would have to be tasked with operational and routine decisions, neglecting decisions related to eliminating the environmental impact on the company and other systemic and more general decisions. 
Democrat-style leader reluctantly relinquishes positional authority, delegating this authority to employees, while retaining ultimate responsibility for himself. Decisions are made in full co-operation with the associates while gaining their full support, which greatly complicates the entire decision-making process. The leader and the whole group act as a unique social whole within which everyone is aware of the tasks, they are assigned but also motivated to express their thoughts and proposals. Usually all this results in greater employee satisfaction and this is then manifested by higher effects within the company.

The style named "Laissez-faire" is applied when the leader wants to remove both power and responsibility. Such a leader is highly dependent on the group, especially when setting company goals. Thus, the members of the group are motivated within them, and the leader has a secondary role. So, this style of leadership ignores the leader's input, and represents an antipode to the authoritarian one. The Laissez-faire leader enables different groups to create and enforce autonomous and diverse policies, which can result in chaos, so it is not preferred, although there are numerous instances where leaders can be identified willingly apply this style, especially in environments where the pressure of opinion and civil society is constant and immense.

The autocratic-democratic leadership model originates from McGregor (Theory X and Theory Y), who profoundly explains and clarifies a person's personality and potential behaviour in an organization. According to this scientist, many of the leader's actions are a consequence of the theory of man's behaviour and he has labelled as Theory Y and he has opposed with the Theory X.

According to this theory, motivated employees have developing opportunities, are capable enough to take responsibilities and orient their actions and behaviours toward achieving company goals. Theory $\mathrm{X}$, on the other hand assumes that people do not like their jobs, and working is not a natural act so they need to be constantly instructed, lacking the feeling and willingness to take on responsibilities, expressing no desire or creativity to solve enterprise's problems, so people seek safety first, are motivated only by money and similar rewards, but also by the deep fear of punishment.

Theory $\mathbf{Y}$ assumes that humans are creative in themselves, so there is no need to supervise them in details, especially if they are properly motivated. Thus, individual goals can best be achieved by achieving the goals of the organization.

Theory $\mathbf{X}$ offers us the model in which the leader presented as an unscrupulous autocrat who prefers strong oversight by applying reward-punishment actions.

On the other hand, Theory Y gives us a democratic model in which the leader is presented as understanding and cooperative and always with the conviction that workers are self-sufficient. The final conclusion of this theory gives priority to Theory $\mathrm{Y}$, thus favouring the democratic model over that of the autocrat.

Employee orientation implies that a leader approaches the co-operative group and workers, emphasizing strong human relations and shows special interest in workers as human beings, appreciates the individuality of each, and pays special attention to their individual needs. Worker-oriented leadership focuses on people rather than on their duties. It demonstrates readiness to assist in the accomplishment of work tasks as well as in resolving other employee issues. Thus, activities are planned and implemented for the training and professional development of workers encourages them to participate in decision-making, etc.

Production orientation focuses on the actions of the leader to expose the productive-technical aspects of the work, while employees are treated as a means of accomplishing their tasks. Such leadership focuses on meticulous performance of tasks (resembling CNC - Computer Numerical Control in machinery). Thus, workers are forced to optimally adapt to well-structured tasks and are therefore stimulated (normative work), while the supervisor supervises their work meticulously.

Consideration or a personal commitment or caring for people, puts mutual respect, assistance and respect first, as well as the opportunity to participate in decision-making, encouraging intensive two-way communication. The leader of this kind is distinguished by the establishment of social relations, respect, trust and close relations of the leader with workers. Initiatives are distinguished by activating the leader toward organizing and defining group activities, work tasks, ways of accomplishing tasks, and ways and channels of communication. This way of leadership is distinguished by the creation of structures, the definition of the role of responsibility and the tendency of a more balanced distribution of work activities.

Leadership based on the Likert model relies on expressing differences between different leadership styles. The scientist Rensis Likert puts the starting point "managing the human component is a very important and central task since it depends on the ultimate success". By integrating the results of his research, Likert has developed analytical frameworks and methods for analysing organizations and has identified the following 4 dominant styles:

- Explorer - autocratic (system 1)

- Benevolent - authoritative (system 2)

- Consultative (system 3) 


\section{- Participatory (system 4)}

SYSTEM 1 - It represents one of the most extreme authoritarian systems (autocratic style). The leader has an autocratic orientation, manifested with low trust in collaborators, and virtually no trust to the submissive ones. The way of motivation is fear and punishment, and rarely gives any reward. The leader allows communication only from top to bottom, and makes decisions without consulting the team.

SYSTEM 2 - The benevolent-authoritative style represents a system where the leader shows little credibility to his subordinates, motivates them with rewards, and rarely applies intimidation and punishment. The leader also allows bottom-up communication, but in controlled ways and forms, takes into account some of the thoughts and proposals that may come from subordinates, and allows delegations to decision-making but under the action of strong control.

SYSTEM 3 - It is known as consultative style. The leader has great (but not complete) confidence to the subordinates, tends to use the ideas and thoughts that come from subordinates, and uses motivation for rewards, and occasionally punishments. The leader is involved in two-way communication (top-down and vice versa), allows decision-making on certain issues even at lower levels, and deals with defining business policy and strategy and decisions of a general nature.

SYSTEM 4 - It represents participatory style. In this case, the leader has complete confidence in his subordinates, always considering ideas and thoughts that come from them. The reward of subordinates is based on group contribution and the leader acts with them as a homogeneous whole. Communication is allowed in all directions in both vertical and horizontal directions, and decision-making is specified and carried out at all levels according to previously separated competencies.

As it can be seen, the most acceptable style may be the participatory one, which relies on the goals and requests outlined above and these goals mobilize individuals and at the same time influence the further development of their skills. To achieve group decision-making and at lower levels, fully decentralizing the decision-making process to those levels where full knowledge and information for quality decisions is concentrated, but at the same time where there is greater interest in issue certain decisions. This model best uses human potential, enhances the flexibility and ability of the company to adapt quickly to new circumstances, which is one of the top priorities in the contemporary market.

According to Likert, the most successful leaders or managers are those who manage to make connections between people who are "at high position" and those who are "below" them in the company. This can also be called "the system of effective working groups" which is distinguished by trust, consultancy, rewards and joint work of leaders and subordinates.

The concept of Leadership Grid was originally developed at Ohio State University. The model itself defines two supporting dimensions:

1. People-Oriented

2. Task-Oriented

People-Oriented deals with the care of leaders that people in the company always be the ones who always and unceasingly strive to achieve the company goals. Self-care involves cultivating and building organizational and trust commitment, promoting individual employee values, providing good working conditions, achieving a fair pay structure, and promoting good social relationships.

Task-Oriented refers to the care that the manager shows for accomplishing organizational tasks within the company. This includes a variety of activities, such as decision-making policies, new product development, innovation and process developments, loads related to production capacity, quality and other advances even higher or towards meeting any standards, increasing sales volume by expanding sales, etc. In other words, it shows the complete orientation of the leader towards the overall improvement of production and the meticulous achievement of all the duties and obligations that are influential in this matter. The network leadership unites these two orientations in a model in which these two axes are met - the one in people and the other in task. The horizontal axis represents the leadership orientation towards tasks, while the vertical axis represents the orientation in people. Each axis is divided into 9 degrees with an intensity equal to 1 to 9 . Intensity 1 is the minimum, while intensity 9 represents the maximum of care and commitment. So, in the coordinate system, 81 different leadership styles can be presented (Figure 2), which five are emphasized:

K1 Leadership $(1,9)$ called family leadership

K2 Leadership $(9,1)$ called authority - submission;

K3 Leadership $(1,1)$ called depleted leadership;

K4 Leadership $(5,5)$ called organizational human leadership;

K5 Leadership $(9,9)$ called team leadership. 
Each person has a particular way of acting, or in terms of model, each person has an own predominant network of styles who applies to many situations. Here, with high reliability, we can conclude that the leadership network represents a practical model of leadership that places the emphasis exclusively on human factor relations and the tasks that must be performed.

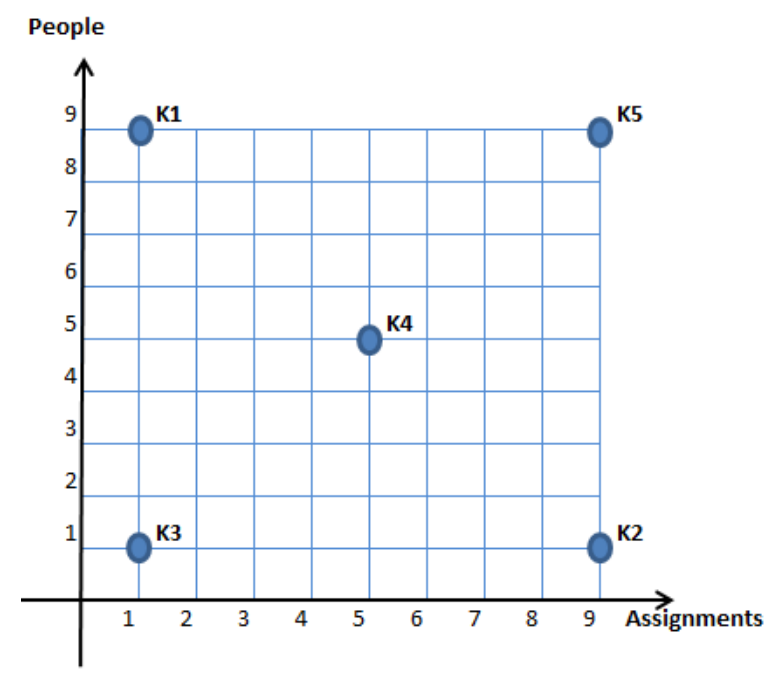

Figure 2. Types of manager

Source: Blake, R. and Mouton, J. (1964). The Managerial Grid: The Key to Leadership Excellence. Houston: Gulf Publishing Co.

For instance, K1 Leadership (1, 9) - Family leadership puts first the demands, needs and interests of employees in order to exclusively achieve their satisfaction. Leaders of this kind strive to achieve a positive work atmosphere in which each employee would feel like a member of a "large family". A positive working atmosphere is a prerequisite for achieving the set working and organizational goals.

K3 Leadership $(\mathbf{1}, \mathbf{1})$ called depleted leadership is characterized by extreme disinterest in workers and negligence in the production or performance of tasks.

Leaders of this style have no affinity for creativity but focus exclusively on maintaining a "status quo", so that the current situation remains unchanged, not even changing production, and maintaining their personal positions in the company. Since they do not act in a motivating way towards employees, a general negative climate is usually created which in turn exposes the non-organization and destimulation of subordinates.

K2 Leadership $(9, \mathbf{1})$, called authority - submission, is characterized by maximum orientation towards the accomplishment of work tasks, completely neglecting the human dimension, thus considering workers as part of the means to perform the assigned work tasks. A leader of this kind tends to accomplish this course of action by demonstrating power and authority. Communication with subordinates is just by giving orders and instructions. So, the leader does not at all attempt to create a friendly atmosphere, but rather aims at personal promotion to the head of the enterprise in order to secure a dominant position and to have complete control over others.

K5 Leadership $(9,9)$ or team leadership, is a style at the same time, supports both the human factor and the assigned tasks, so it is commonly accepted as a satisfying style in production companies. Many management scholars accept this style as the best because it is usually characterized by a high degree of participation in decision making as well as teamwork within the company. Leaders are actively between leader-subordinate relationships, stimulating subordinate's participation in decision-making, enjoying work and outcomes, and accepting questions openly. K4 Leadership $(5,5)$ is characterized by a compromise relationship between care work and care for people or workers.

K4 Leadership $(5,5)$ is characterized by a compromise relationship between care work and care for people or workers. Otherwise, this style is also referred to as "Middle way leadership". Leaders of this style are selfish and show a noticeable balance of care between people and tasks.

\section{Conclusion}

The purpose of this paper is the influence of leadership in decision making.

Each enterprise is a system, to function each system must be open. Even deployment in open systems is influenced by environmental factors. 
The primary objective of this study is to identify the most important impacts of leadership on decision making.

But at the same time decision makers should be informed and know how to make the most important decisions and which factors are the most influential.

Decision makers not only need to recognize the most important impacts of leadership, but they also must know the methods, ways and techniques of deployment in order to minimize negative impacts and threats turn into a priority for the enterprise.

This paper also addresses the impact of leadership on the business success of the enterprise.

It was made a diagnosis of organization's situation and an analysis of readiness factors to apply contemporary methods of leadership in decision making.

\subsection{Recommendation}

It is the responsibility of managers to take actions and activities that enable companies as a whole to reach their maximum potential. All managers make certain decisions. Decisions are of different levels and importance.

Managers in production companies, with their decisions, strive to deliver stable production, minimize operating costs and achieve an acceptable ratio between raw materials, other materials and the efficiency of their use in the process. This is always accompanied by cost-saving and profit maximization, rationalizing production and minimizing unnecessary costs. As a final goal, managers have to maximize profits and provide satisfaction for employees and shareholders. All of these elements make the manager responsible for the decision-making process within the company.

In enterprises led by skilful managers, success is measured not only by the high profit achieved but also by the creative developmental elements of the perspective. Initiative, responsibility, risk exposure, results achieved and a number of other elements of decision making are factors that indicate how much a decision maker is capable of changing today and recognizing tomorrow.

Contemporary decision makers are required to be known for flexibility, cohesion principle of decisions, and skilful supervisors, in order to produce the desired results, to motivate employees, to make collaborators and employees feel the satisfaction of the jointly achieved success. So, the decision maker is required to cultivate the team spirit of work through quality decisions.

Productivity is also of a satisfactory level because companies have been profitable from the beginning and have invested in restructuring a high financial cost.

Also, working conditions have been improved significantly even the motivation of employees is too high to work. Surveys conducted for the purpose of this paper demonstrate the full satisfaction of employees with decision makers, and it is investigated that enterprises have decision makers who are knowledgeable and apply modern methods of leadership.

Based on the factual situation of the companies and based on the principle that there is always an even better solution, I offer the following recommendations as: to improve the management of factors influencing the decision-making process, to research the possibilities of improving the quality of decisions, to continue with the proper treatment and specialization of managers in building the decision-making strategy and enhancing the efficiency of decision-making; and to build a business intelligence system.

\section{References}

1. Ian Worthington, Chris Britton, Mjedisi i Biznesit e perkthyer nga Nagip Skenderi, Prishtinë, 2015

2. John Baylis, James J. Wirtz, Colin S. Gray, Eliot Cohen: Strategy in the Contemporary World. An Introduction to Strategic Studies, e përkthyer nga Elona Lena, Tiranë, 2013.

3. Goleman, D., Boyatzis, R. \& McKee, A. 2013, Primal Leadership: Unleashing the Power of Emotional Intelligence: Harvard Business Press

4. Prof.dr. Suzana Panariti : Menaxhimi i Projekteve, Tiranë, 2004

5. Richard.L. Daft, Dorothy Matrcic : Understanding Managment, SH.B.A. 2004.

6. Prof.dr. Qamil Talka: Organizimi dhe Drejtimi i Biznesit, Tiranë, 2008

7. Pavlicic D. Teorija odlucivanja, Universitetski udzbenik, Ekonomski Fakultet Beograd. 2015.

8. Lientz B et All. International Project Management. Elsever Science. San Diego. USA. 2003.

9. Scinner, Wickham. Manufacturing - Missing Link in Corporate Strategy. Harward Bussines Review.1969.

10. Kuka, Ibrahim, Vendosja Afariste, Riinvest, Prishtinë, 2003.

11. Kume, Vasilika. Manaxhimi Strategjik, Tiranë, 2003.

12. Kelmendi Sh. Operations Management, University book, College of International Management, Prishtinë. 2015.

13. Kelmendi Sh. Project Management, University book, College of International Management, Prishtinë.2011.

14. Kelmendi Sh. At All. Mathematical Methods in Engineering. University book. Pristina University. 2007.

15. Ichak Adizes. Managing Corporate Lifecycles. 2004

16. Paul Banfield. Rebecca Kay. Introduction to Human Resource Management. 2008

17. Kevin Gibson. Ethic and Business.2007 